\title{
An Itchy Problem: A Clinical Case of Crusted Scabies
}

\author{
António Araújo Ferreira ${ }^{1}$, Alexandra Esteves ${ }^{1}$, Yolanda Mahia $^{2}$, Aristóteles Rosmaninho $^{3}$, Augusta Silva $^{1}$ \\ ${ }^{1}$ Serviço de Medicina 1, Unidade Local de Saúde do Alto Minho, EPE, Portugal \\ ${ }^{2}$ Serviço de Anatomia Patológica, Unidade Local de Saúde do Alto Minho, EPE, Portugal \\ ${ }^{3}$ Serviço de Dermato-Venereologia, Unidade Local de Saúde do Alto Minho, EPE, Portugal
}

Received: 05/02/2017

Accepted: 07/02/2017

Published: 09/03/2017

How to cite this article: Ferreira AA, Esteves A, Mahia Y, Rosmaninho A, Silva A. An Itchy problem: a clinical case of crusted scabies. EJCRIM 2017;4: doi:10.12890/2017_000591.

Conflicts of Interests: The Authors declare that there are no competing interests.

Acknowledgements: The Authors would like to thank to Paula Felgueiras, MD and Diana Guerra, MD of the Internal Medicine Department, Unidade Local de Saúde do Alto Minho, for collaboration in this clinical case.

This article is licensed under a Commons Attribution Non-Commercial 4.0 License

\section{ABSTRACT}

Scabies is an infestation of the skin by the mite Sarcoptes scabiei. A more severe form called crusted or Norwegian scabies may occur in immunosuppressed patients and the elderly. Crusted scabies mostly differs from normal scabies by the exuberance of its lesions, body distribution and high contagiousness, and requires different and more prolonged treatment. Early recognition of the lesions and isolation precautions are crucial for disease control and prevention of transmission. The authors describe a clinical case of crusted scabies with pruritus and exuberant cutaneous lesions.

\section{LEARNING POINTS}

- Crusted scabies is an infestation of the skin by the mite Sarcoptes scabiei that is highly contagious and results in an intensely pruritic eruption with exuberant cutaneous lesions.

- Crusted scabies occurs in patients with AIDS, lymphoma or compromised cellular immunity, and sometimes in older patients. It is characterized by an elevated burden of mites and does not have a characteristic distribution pattern.

- This disease requires strict isolation measures and treatment which differs from and is more prolonged than for scabies.

\section{KEYWORDS}

Crusted scabies; pruritus; contagious diseases

\section{INTRODUCTION}

Scabies is an infestation of the skin by the mite Sarcoptes scabiei. A more severe form called crusted or Norwegian scabies occurs when mite replication is not controlled by the host's immune system and hyperinfection develops ${ }^{[1]}$. It occurs in the elderly and in people with neurological or mental disorders (especially Down syndrome), senile dementia, nutritional disorders, infectious diseases, leukaemia and immunosuppressive conditions, such as in patients with acquired immunodeficiency syndrome ${ }^{[2]}$. Crusted scabies mostly differs from normal scabies by the exuberance of its lesions, body distribution, high contagiousness and requirement for more aggressive treatment. The cutaneous lesions tend to involve the hands and feet with asymptomatic crusting rather than the typical inflammatory papules and vesicles of normal scabies, but burrows may be present. There is thick, subungual, keratotic material and nail dystrophy. Digits and sites of 
trauma may show wart-like formations. Grey scales and thick crusts may be present over the trunk and extremities. Desquamation of the facial skin may occur and hair may shed profusely ${ }^{[2]}$. The pruritus may be absent or severe.

The authors describe a clinical case of crusted scabies in an elderly woman.

\section{CASE REPORT}

An 87-year-old woman was admitted in our unit with a lower respiratory tract infection. The patient lived in a retirement home and had a history of mild vascular dementia, chronic obstructive pulmonary disease, bronchiectasis and primary sclerosing cholangitis diagnosed 6 years before the present admission and was medicated with ursodeoxycholic acid, cholestyramine, inhaled corticosteroids and bronchodilators. In addition to the admission diagnosis, the patient had pruritus associated with skin lesions on the head and arms for the previous 2 months. On physical examination, she presented erythematous-desquamative plaques and an adherent grey scale with a thick crust with fissures on the scalp with no hair (Fig. 1), palmar keratodermia (Fig. 2) and small erythematous plaques on the forearms, chest and back, associated with itchy lesions.

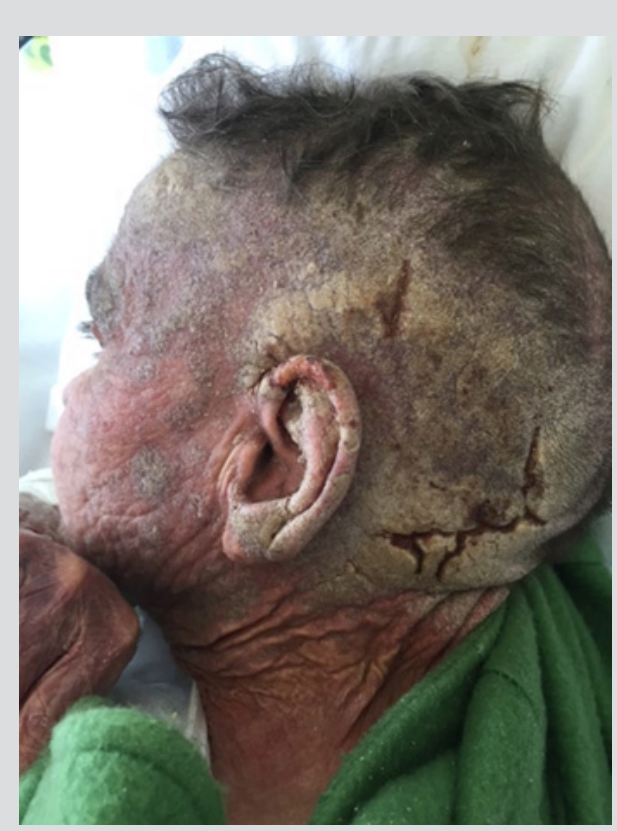

Figure 1. Scalp at hospital admission

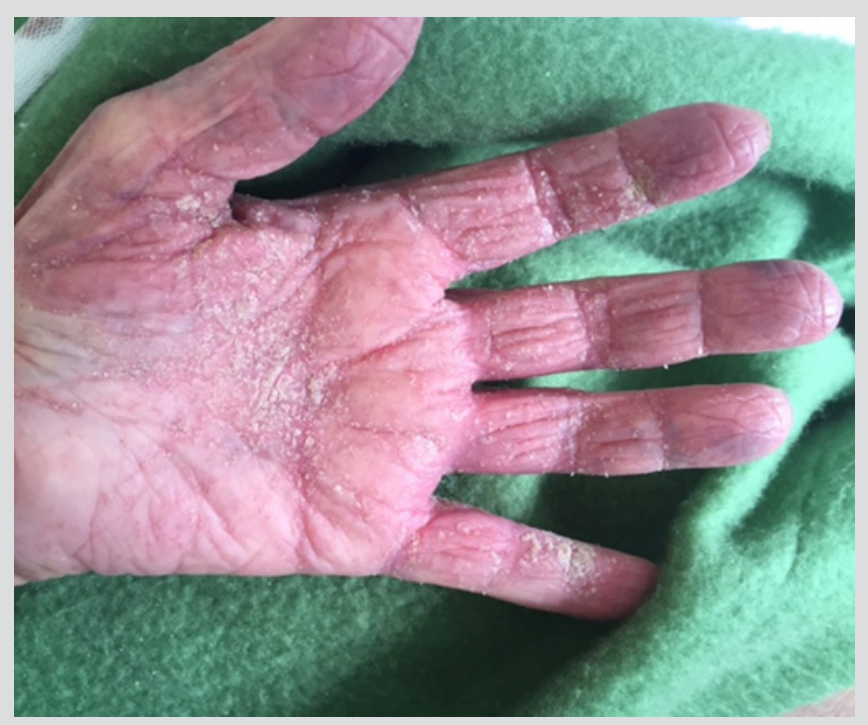

Figure 2. Palmar keratodermia

The differential diagnosis included crusted scabies, mycosis fungoides, Sézary syndrome and psoriasis vulgaris, and contact isolation measures were initiated. A skin biopsy was taken and sent for immunophenotyping and anatomopathological analysis. The laboratory evaluation showed discrete leucocytosis ( $14.07 \times 10^{9} / \mathrm{I}$ with $93.9 \%$ of neutrophils) and elevated C-reactive protein ( $\left.8.7 \mathrm{mg} / \mathrm{dl}\right)$ which resolved after respiratory infection treatment. Haemoglobin was $12.2 \mathrm{~g} / \mathrm{dl}$ and platelets were $228 \times 10^{9} / \mathrm{l}$. Renal function, aspartate aminotransferase, alanine transaminase, alkaline phosphatase, gamma glutamyl transferase and total bilirubin were normal. Sedimentation rate was elevated (42 mm/h), but the serum lactic dehydrogenase was normal and peripheral blood smear showed normal blood cells. Immunoglobulins $\mathrm{G}$, A and $\mathrm{M}$ were normal. HIV serology was negative. Thoracic $\mathrm{x}$-ray and abdominal ultrasound were normal. The immunophenotyping study was inconclusive and histological examination of the skin revealed marked hyperkeratosis with abundant arthropod parasites compatible with $S$. scabiei (Fig. 3). The diagnosis of crusted scabies was confirmed and treatment was initiated with oral ivermectin 15 mg on days 1, 2, 8, 9 and 15 , topical treatment with $6 \%$ sulfur ointment for 2 weeks, and keratolytic creams. Isolation precautions were maintained and the public health department and the retirement home were notified. The patient's skin lesions gradually improved (Fig. 4) and she was discharged at the end of treatment. One month after treatment initiation the patient had complete resolution of all lesions and no pruritus. The patient showed no signs of clinical relapse 6 months after treatment completion (Fig. 5). 


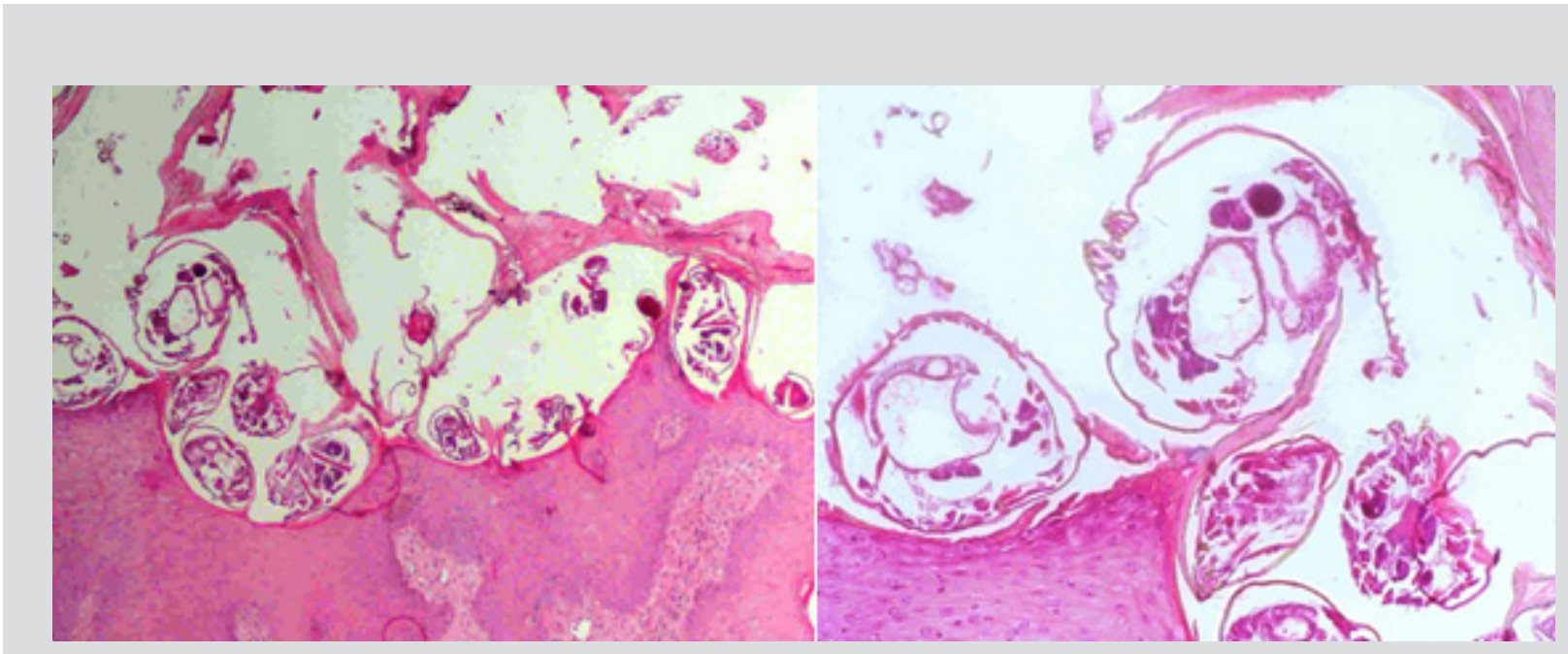

Figure 3. Histological examination of a skin fragment (haematoxylin and eosin stain). Left image: view of the skin with scabies mites seen on the surface. Right image: closer view of the scabies mites

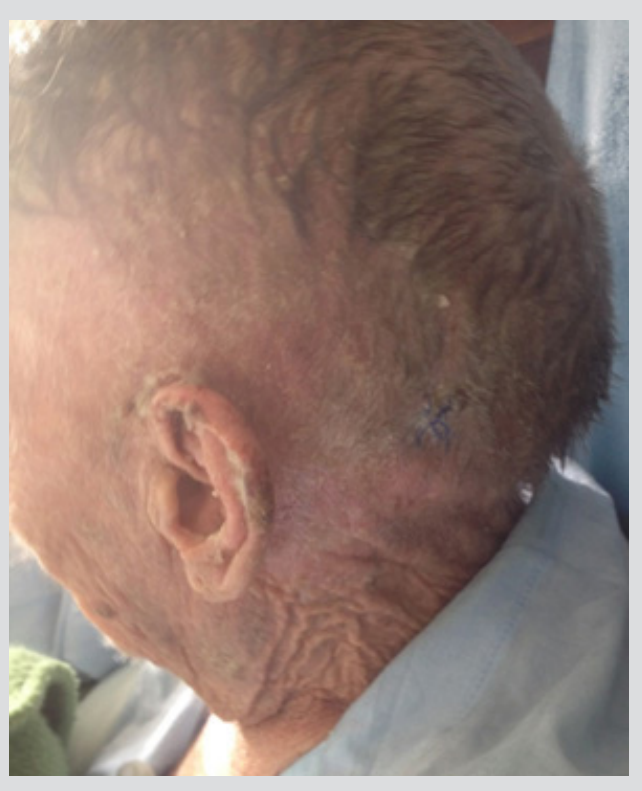

Figure 4. Scalp 10 days after treatment initiation

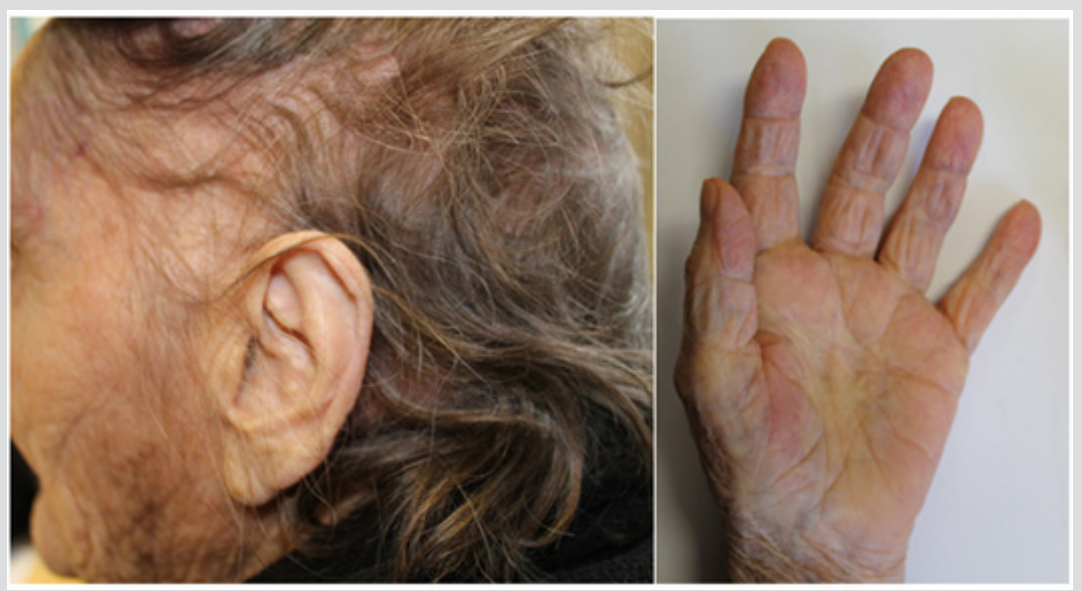

Figure 5. Scalp and palmar surface 6 months after treatment completion

\section{DISCUSSION}

The diagnosis of crusted scabies is generally made from the history, distribution of lesions and the presence of similar symptoms in other household members. This patient had a 2-month history of skin lesions and pruritus, the type of lesions was atypical for scabies but compatible with crusted scabies, and other cases of scabies were reported after the retirement home was notified. Although the diagnosis was probable, the pruritus could have been caused by the patient's sclerosing cholangitis, even with normal bilirubin values, and on the initial evaluation the medical team had not been informed of other household cases of scabies.

A diagnosis of crusted scabies can be confirmed by observing the mite through dermoscopy, or after skin scraping, an adhesive tape test or skin biopsy. Although crusted scabies was the most probable diagnosis in this case, a skin biopsy was performed to exclude other diagnoses such as malignancy.

Treatment for crusted scabies is difficult and requires extended application of a combination of topical and oral anti-parasitic therapy, as well prolonged isolation in hospital. Despite this, re-infection is frequent and relapses have been documented ${ }^{[3]}$. 
For the treatment of crusted scabies, the CDC recommends a combination regimen of topical $5 \%$ permethrin or topical $5 \%$ benzoyl benzoate applied daily for 7 days, then twice weekly until cure, plus oral ivermectin (200 $\mu \mathrm{g} / \mathrm{kg} / \mathrm{dose})$ given on days 1, 2, 8, 9 and 15 [4]. Severe infestations may require longer courses of oral ivermectin, with two additional doses (given on days 22 and 29 ) ${ }^{[5]}$.

Our patient was treated with ivermectin, but the topical treatment chosen was $6 \%$ sulfur ointment because $5 \%$ permethrin is not available in Portugal and benzoyl benzoate has abrasive characteristics and should not be used on inflamed skin or fissures as seen in this patient. There are some reports in the literature of successful treatment with sulfur ointment in crusted scabies ${ }^{[6]}$. In one study, no significant difference was detected in the number of treatment failures between topical sulfur and other topical treatments for scabies ${ }^{[7]}$, but the data are limited. In adults, transmission of scabies occurs usually from person to person by direct contact. However in crusted scabies where the parasite burden is high ${ }^{[8]}$, fomite transfer is an important route of transmission. As a result, patients with crusted scabies should be isolated immediately, and strict barrier nursing procedures instituted. Serious institutional epidemics of scabies have resulted from failure to recognize the disease and take proper precautions ${ }^{[8]}$. Where there are cases of crusted scabies, every household and close personal contact should be treated at the same time to avoid an endless chain of cross- contamination and re-infestation.

This patient remained in hospital until the end of treatment as the retirement home could not ensure the correct isolation measures. The public health department was involved and all household and healthcare professionals in contact with the patient were treated for scabies.

\section{REFERENCES}

1. Currie BJ, McCarthy JS. Permethrin and ivermectin for scabies. N Engl J Med 2010;362:717.

Habif TP. Infestations and bites. In: Habif TP, editor. Clinical dermatology. Philadelphia: Saunders; 2015, Chapter 15, pp. 577-634.

. Meinking TL, Taplin D, Hermida JL, Pardo R, Kerdel FA. The treatment of scabies with ivermectin. N Engl J Med 1995;333:26-30.

Workowski KA, Bolan GA, Centers for Disease Control and Prevention. Sexually transmitted diseases treatment guidelines, 2015. MMWR Recomm Rep 2015;64:1.

5. Roberts LJ, Huffam SE, Walton SF, Currie BJ. Crusted scabies: clinical and immunological findings in seventy-eight patients and a review of the literature. J Infect 2005;50:375.

6. Su WJ, Fang S, Chen AJ, Shan K. A case of crusted scabies combined with bullous scabies. Exp Ther Med 2015;10:1533-1535.

7. Strong M, Johnstone P. Interventions for treating scabies. Cochrane Database Syst Rev 2007;3:CD000320.

8. Goldstein BG, Goldstein AO. Scabies. In: Ofori AO, editor. UpToDate, Waltham, MA (accessed 28 April 2016). 